\title{
Overview: dementia and the role of occupational therapy practitioner
}

\begin{abstract}
Dementia is a group of disturbances of memory associated with multiple cognitive deficits, such as aphasia, apraxia, agnosia, and disturbance of executive function. Alzheimer's is the most common type of dementia. The signs of dementia generally include, but are not limited to, decreased short term memory, decreased problem solving skills, decreased perceptual skills, and personality changes. The onset of dementia is gradual, and the course of the disease spans several years or more. In Alzheimer's disease, the person progresses through several stages with those in the final stages being completely dependent on others. Occupational therapists evaluate persons with dementia to determine their strengths, impairments, and performance areas needing intervention. Although remediation of cognitive performance is not likely, the person may demonstrate improved function through compensation or adaptation. Occupational therapy practitioners also assist caregivers to help them cope with difficulties associated with dementia to ensure safe and supportive environment.
\end{abstract}

Keywords: dementia, occupational therapy, occupational performance, cognition, memory, compensation, adaptation, remediation, environment
Volume 3 Issue 4 - 2018

\author{
Hassan Izzeddin Sarsak \\ Department of Occupational Therapy, Batterjee Medical \\ College, Saudi Arabia
}

\begin{abstract}
Correspondence: Hassan Izzeddin Sarsak (PhD, OT), Department of Occupational Therapy, Batterjee Medical
\end{abstract} College, Jeddah, KSA, Email hassan.sarsak@bmc.edu.sa

Received: August 31, 2018| Published: October 04, 2018

\section{Introduction}

Dementia is a cognitive disorder that includes a decline in mental ability. It is different from other cognitive disorders that people may get confused with, such as delirium and amnesia (Table 1). It affects basic cognitive skills (memory, attention), and higher executive functioning (i.e., planning, organization, and sequencing). Dementia results from impaired cognition, due to damage to the brain. The majority of dementia cases $(60 \%$ to $80 \%)$ are classified as Alzheimer's disease. ${ }^{1}$
Dementia includes a group of symptoms associated with a decline in memory or other thinking skills severe enough to gradually reduce a person's ability to perform even basic activities of daily living at later and severe stages of the disease. Memory loss, miscommunication, inability to focus and pay attention, poor reasoning and poor judgment, and visual misperception are some common and core symptoms of dementia. In addition, people with dementia may have problems keeping track of things, managing their finances, preparing meals, remembering appointments or outdoor travelling. ${ }^{2}$

Table I Differences between dementia, delirium, and amnesia.

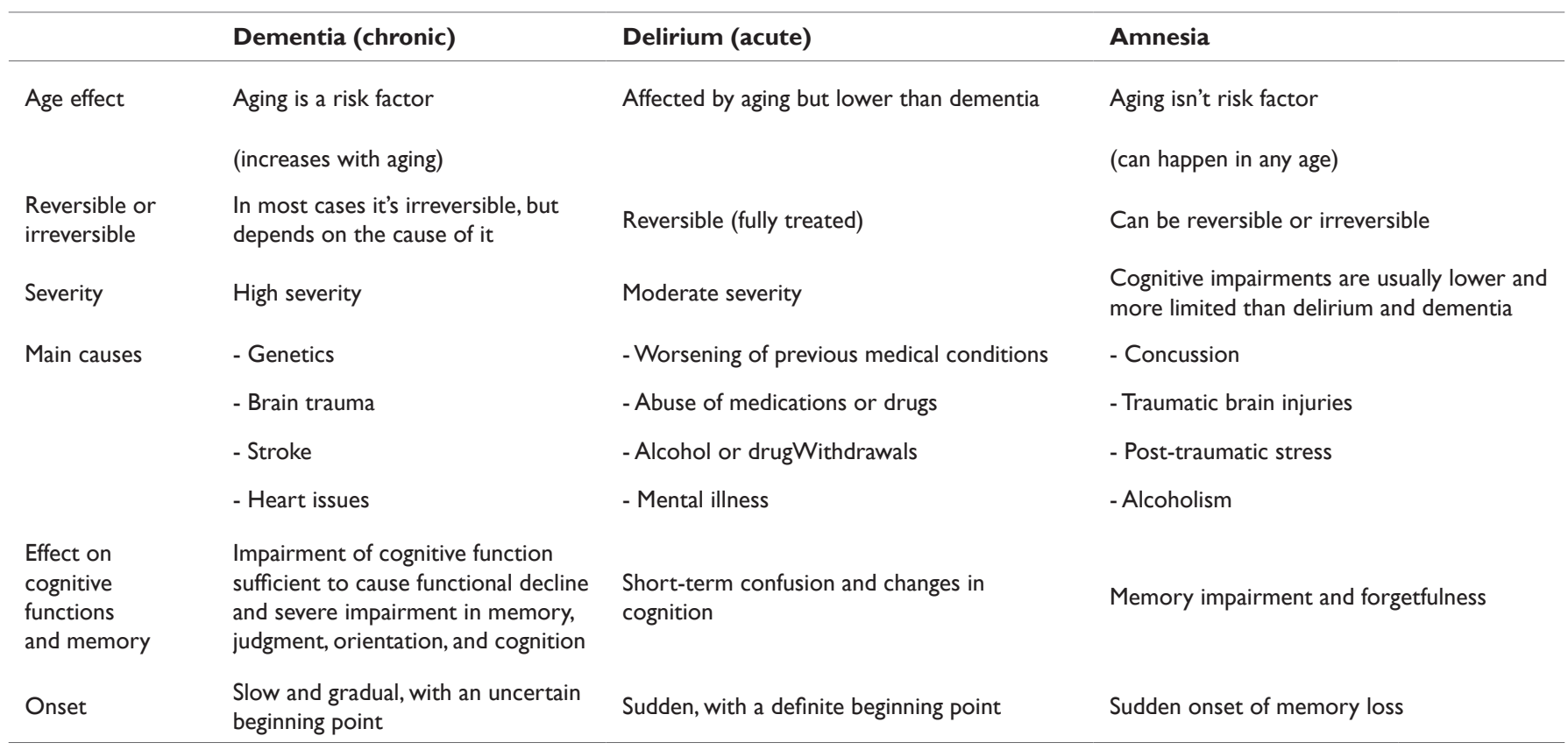


Research has shown that there are things we can do to reduce the risk of mild cognitive impairment and dementia. Some of the most active areas of research in risk reduction and prevention include cardiovascular factors, physical fitness, diet, and being active social member in the community through engaging in meaningful and purposeful activities. Non-drug therapies may reduce some symptoms of dementia, such as occupational therapy (OT).

\section{Role of occupational therapy practitioner}

Occupational therapy practitioners work with individuals with dementia in terms of occupational performance. They can educate those in the early stages of the disease and their caregivers about dementia and its functional implications through psych-education and symptoms management sessions. Occupational therapists conduct a thorough assessment and evaluate persons with dementia to determine their strengths, impairments, and performance areas needing intervention. ${ }^{3}$ Although remediation of cognitive performance is not likely, the person may demonstrate improved function through compensatory and adaptive therapeutic approaches. Occupational therapy practitioners also can help caregivers to cope and deal with dementia. In the community, occupational therapists can assist those with dementia to live in their own homes safely for as long as possible through environmental evaluation and adaptation. Occupational therapists may also provide wellness programs, such as falls prevention and caregiver educational sessions. They help patients with dementia to improve and/or maintain function for as long as possible through a variety of approaches based on the Occupational Therapy Practice framework: Domain and Process. ${ }^{3}$ Occupational therapists can promote health by focusing on maintained strengths of patients and promoting wellness of caregivers. They can enrich their patients' lives by maximizing performance in meaningful and purposeful activities. Also, occupational therapist may help in restoration of some physical skills if possible (i.e., range of motion, strength, and endurance). In addition, occupational therapist can provide support to ensure that the person's skills are maintained for as long as possible through the engaging in functional daily routine and social activities. Furthermore, occupational therapist can make some environmental modifications to ensure safe and supportive environments through adaptation and compensation.

To better understand the role of occupational therapist in dealing with patients with dementia, it is important to highlight that the occupational therapist first evaluate and determine the cognitive and functional level by using different assessment tools. One of the most common and useful evaluation tools that occupational therapists use is The Global Deterioration Scale (GDS) developed by Dr. Barry Reisberg. The GDS provides caregivers an overview of the stages of cognitive function for patients with dementia such as Alzheimer's disease. It is broken down into 7 different stages which are usually referred to as "Reisburg's Stages for Dementia Scale". ${ }^{4}$ Here is a brief description of each stage with the role of occupational therapist and a list of recommended activities for each stage that may maintain and/ or restore functional performance (Table 2). ${ }^{5,6}$

Table 2 Reisburg's stages for dementia scale and recommended OT activities.

\begin{tabular}{|c|c|c|}
\hline Stage & Brief description & Recommended OT activities \\
\hline 1 & No impairment; no memory problems. & $\begin{array}{l}\text { Functional and social participation/activitiesthat are } \\
\text { meaningful and purposeful are recommended. }\end{array}$ \\
\hline 2 & $\begin{array}{l}\text { Very mild decline; normal age related changes or earliest signs of } \\
\text { Alzheimer's disease. }\end{array}$ & $\begin{array}{l}\text { Functional and social activities that are meaningful and } \\
\text { purposeful are recommended. }\end{array}$ \\
\hline 3 & $\begin{array}{l}\text { Mild cognitive decline; family and friends begin to notice } \\
\text { problems in memory and concentration (difficulty remembering } \\
\text { names, forgetting what one has just said, misplacing and losing } \\
\text { valuable objects). }\end{array}$ & $\begin{array}{l}\text { Copying skills and problem solving activities are } \\
\text { appropriate. }\end{array}$ \\
\hline 4 & $\begin{array}{l}\text { Moderate cognitive decline; forgetting recent events (Short } \\
\text { Term Memory loss), difficulty performing complex Instrumental } \\
\text { Activities of Daily Living (IADL) tasks, difficulty remembering } \\
\text { personal history, becoming moody. }\end{array}$ & $\begin{array}{l}\text { Reminiscence activities (to review past life experiences and } \\
\text { use of LTM) are appropriate. }\end{array}$ \\
\hline 5 & $\begin{array}{l}\text { Moderate to severe decline (mid-stage dementia); have poor } \\
\text { Active Working Memory (AWM) but good Long Term Memory } \\
\text { (LTM), difficulty performing Activities of Daily Living (ADL), } \\
\text { unable to recall their own address, telephone, confused about } \\
\text { time, place, still remember significant details about themselves } \\
\text { and their family, still requires no assistance in eating and toileting. }\end{array}$ & $\begin{array}{l}\text { Reminiscence activities (to review past life experiences and } \\
\text { use of LTM) are appropriate. }\end{array}$ \\
\hline 6 & $\begin{array}{l}\text { Severe cognitive decline; requires maximum assistance in } \\
\text { ADL, help in toileting, trouble controlling bladder, remember } \\
\text { their name but not personal history, difficulty in remembering } \\
\text { caregiver/spouse names (Anomia), major changes in sleep } \\
\text { patterns (restless night, sleeping during the day), suspiciousness, } \\
\text { delusions, confused, lost. }\end{array}$ & Sensory stimulation activities are recommended. \\
\hline 7 & $\begin{array}{l}\text { Very severe (final stage); maximum help in ADL, toileting, eating, } \\
\text { no response to the environment, no movement control, cannot } \\
\text { sit symmetrically, rigid muscles, impaired swallowing, abnormal } \\
\text { reflexes, may still say few words/phrases, lose ability to smile } \\
\text { (anhedonia). }\end{array}$ & $\begin{array}{l}\text { Sensory stimulation activities are recommended (Stein, \& } \\
\text { Cutler, 2002). }\end{array}$ \\
\hline
\end{tabular}




\section{Conclusion}

Enhancing function, promoting social participation, and finding ways for individuals with dementia to have a meaningful and enjoyable life are the keys to successful occupational therapy intervention. ${ }^{3}$ Occupational therapists play an important role in the evaluation and intervention process for persons with dementia and can help in so many ways through the application of a variety of therapeutic approaches that help improve function through compensation or adaptation, develop coping skills for caregivers, and ensure safe and supportive modified environment.

\section{Funding details}

No funding was required.

\section{Acknowledgements}

None.

\section{Conflict of interest}

Author declares that there is no conflict of interest.

\section{References}

1. Alzheimer's Association. What is dementia? Chicago; 2018.

2. American Psychiatric Association. Diagnostic and statistical manual of mental disorders. DSM-IV-TR. Washington, DC, USA: American Psychiatric Association; 2002.

3. Schaber P, Lieberman D. Occupational therapy practice guidelines for adults with Alzheimer's disease and related disorders. Bethesda, MD: AOTA; 2010.

4. Hemphill-Pearson B. Assessments in Occupational therapy Mental Health Health: An Integrative Approach. 2nd ed. Thorofare, NJ: Slack Incorporated; 2008. p. 170-171.

5. Occupational Therapy Practice Framework: Domain and Process. 3rd ed. American Journal of Occupational Therapy. 2014;68(Supplement_1):S1S48.

6. Stein F, Cutler S. Psychosocial occupational therapy: a holistic approach. Albany, NY, USA: Delmar/Thomson Learning; 2002. 